\title{
Fertility of spermatozoa from the excurrent ducts of the guinea-pig
}

\author{
B. R. Williamson, B. A. Shepherd and J. Martan \\ Department of Zoology, Southern Illinois University, Carbondale, Illinois 62901, U.S.A.
}

\begin{abstract}
Summary. Guinea-pigs were inseminated with spermatozoa from the vas deferens, where they are characteristically arranged in rouleaux, or from that part of the epididymis where rouleaux are infrequent. Fertility was much reduced in the 16 females inseminated with a suspension of single spermatozoa: only 4 became pregnant (compared with $10 / 11$ controls) and all these had had some $(0.5-0.75 \%)$ rouleaux in the insemination suspension. It is concluded that rouleau formation is indicative of physiological as well as morphological maturity.
\end{abstract}

\section{Introduction}

Post-testicular maturation of spermatozoa in the guinea-pig differs from that of most other commonly studied laboratory species in that it is accompanied by striking and distinct changes in the acrosome and by association of the spermatozoa into stacks referred to as rouleaux. Fawcett \& Hollenberg (1963) reported that, following a change in shape of the acrosome, rouleau formation occurred in segment 4 of the guinea-pig epididymis and suggested that this event indicated morphological maturation of spermatozoa and that single spermatozoa proximal to segment 4 were probably immature.

To our knowledge, there have been no fertility studies to establish whether morphologically immature spermatozoa are capable of effecting fertilization. We therefore examined whether the single spermatozoa in the epididymis proximal to the region in which rouleaux form have acquired fertilizing ability. If they have not, such physiologically immature spermatozoa could be selectively used for studies of sperm physiology.

\section{Materials and Methods}

The 27 male and 27 female guinea-pigs weighed 664-1359 g, were 4-14 months of age and were sexually mature. All animals were from an inbred colony housed in the vivarium at Southern Illinois University, Carbondale, and were maintained as described by Martan (1966) and Martan \& Shepherd (1973).

Females in behavioural oestrus (Martan \& Shepherd, 1976) were prepared for artificial insemination as described by Shepherd \& Martan (1979). Males were killed by a blow to the head, and the testes and excurrent ducts were exposed via a scrotal incision. For the 16 experimental animals, the vasa deferentia were ligated and the testes, epididymides and vasa were removed and rinsed with warm Ringer-Locke solution (Zarrow, Yochim \& McCarthy, 1964). All subsequent manipulations were performed on a heated table at approximately $37^{\circ} \mathrm{C}$ using pre-warmed solutions. The preparations were then placed in Petri dishes containing fresh 
Ringer-Locke solution and each epididymis was dissected from the testis and fat pad approximately at the level of mid-segment one. The dissected epididymis was then teased into segments along natural connective tissue partitions (Pl. 1, Fig. 1) and separated into proximal and distal portions. The distal portion was discarded and the proximal portion, which included roughly the distal part of segment 1 and segments 2-4 described by Fawcett \& Hollenberg (1963), was transferred to a second Petri dish containing Tyrode's solution (Difco Laboratories, Detroit, Michigan). Beginning at the distal end of this portion, and progressing proximally, small sections were removed and smears were taken until no rouleaux were seen in the smears (Pl. 1, Fig. 2). The remaining parts of the epididymal ducts were then pooled in a small Petri dish containing 1-1.5 ml Tyrode's solution, and finely minced with iridectomy scissors to release the spermatozoa. Smears were made from the suspension to evaluate sperm motility and to check for rouleaux immediately before artificial insemination. For the 11 control males, the vasa deferentia were removed and flushed with $1 \mathrm{ml}$ warm Tyrode's solution to provide a sperm suspension (Pl. 1, Fig. 3) for insemination. For insemination, about $0.5 \mathrm{ml}$ sperm suspension was injected through the anti-mesometrial wall into the lumen of each uterine horn as described by Shepherd \& Martan (1979). The minimum number of spermatozoa inseminated into each uterine horn was approximately $23 \times 10^{6}$, based on duplicate haemocytometer counts (Cannon, 1974). This entire procedure required about $10 \mathrm{~min}$.

The smears made were air dried, fixed in Baker's formol and stained with Kernechtrot and Fast Green FCF (Shepherd, Martan \& Murphy, 1974). Three separate counts of 1000 spermatozoa (whether single or in rouleaux) were made and the percentage rouleaux for each suspension was computed. Rouleaux were treated as a single spermatozoon for the calculations.

Females were examined daily from 14 days after insemination. Animals which did not show a perforate vagina by Day 20 were killed and the uteri were inspected for embryos.

\section{Results}

Of the 11 females inseminated with spermatozoa from the vasa deferentia of control males (i.e. with rouleaux), 10 (91\%) conceived and had 3-6 (average 4.1) embryos. The conception rate for the experimental females was $25 \%$ and the females becoming pregnant had all been inseminated with a sperm suspension which contained some rouleaux (Table 1).

Table 1. Results of artificial insemination of guinea-pigs with suspensions of single spermatozoa from the proximal regions of the epididymis

\begin{tabular}{cccc}
\hline $\begin{array}{c}\text { No. of females } \\
\text { inseminated }\end{array}$ & $\begin{array}{c}\% \\
\text { Rouleaux }\end{array}$ & $\begin{array}{c}\text { No. of females } \\
\text { pregnant }\end{array}$ & No. of embryos \\
\hline 7 & 0 & 0 & 0 \\
1 & 0.05 & 0 & 0 \\
1 & 0.35 & 0 & 0 \\
2 & 0.55 & 1 & 4 \\
3 & 0.70 & 2 & 2,2 \\
1 & 0.75 & 1 & 3 \\
1 & 1.20 & 0 & 0 \\
\hline
\end{tabular}

\section{Discussion}

From the results of these fertility tests we conclude that the single spermatozoa from the proximal epididymis are physiologically as well as morphologically immature. In the experimental females in which some rouleaux were inseminated we estimate from the 


\section{PLATE 1}
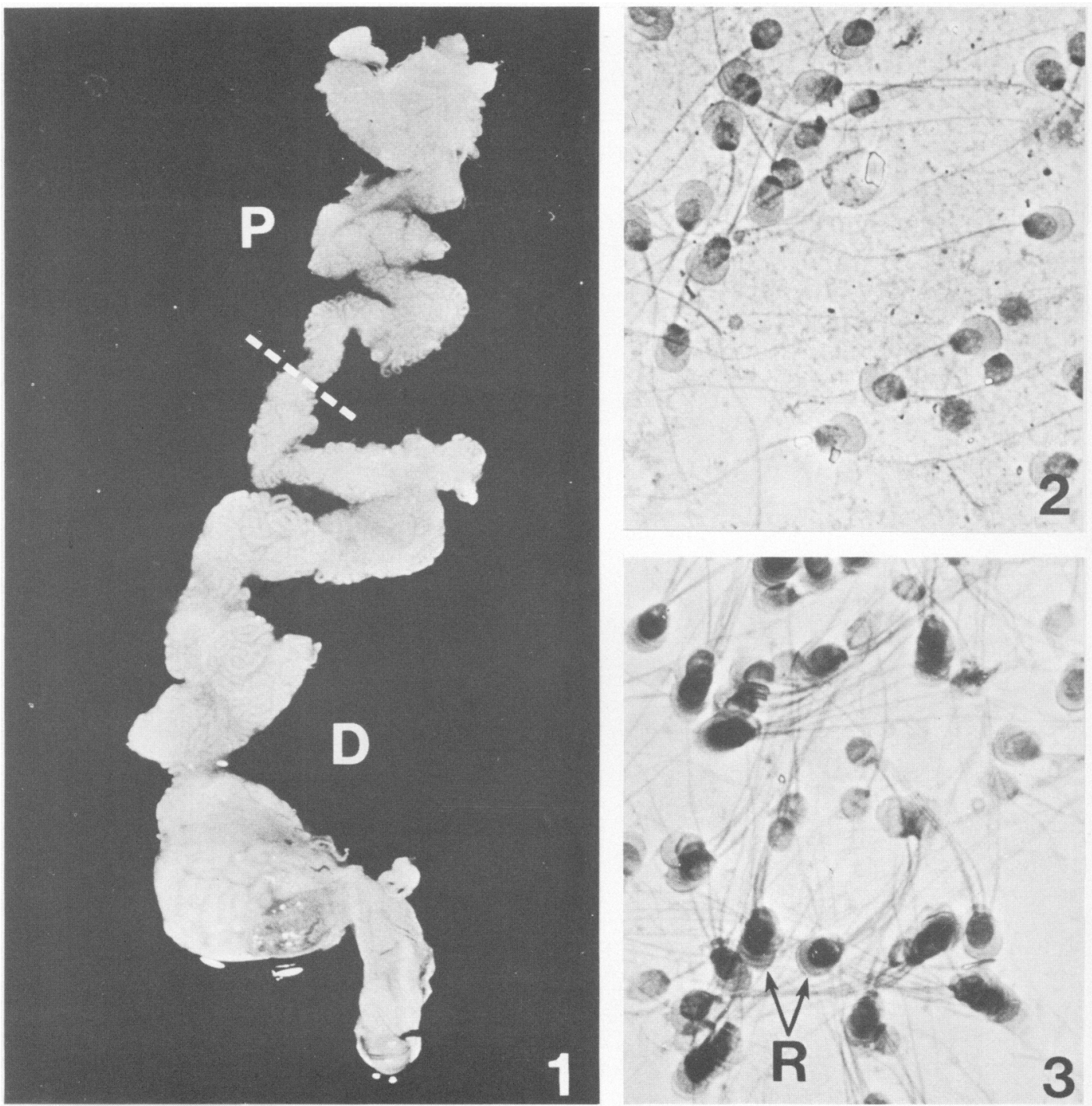

Fig. 1. Proximal (P) and distal (D) portions of grossly dissected epididymis. The broken line indicates the approximate place where single spermatozoa start to associate in rouleaux.

Fig. 2. Single spermatozoa from the proximal region of the epididymis. $\times 1400$.

Fig. 3. Spermatozoa in rouleaux $(R)$ from the vas deferens. $\times 1400$. 
haemocytometer counts that the number of spermatozoa in the rouleaux would have been 34 500-828 000/uterine horn, assuming a conservative average of 3 spermatozoa/rouleau. We therefore attribute the conceptions to spermatozoa which were in rouleaux at the time of insemination rather than to the single spermatozoa present.

While the results of this study show that acquisition of fertilizing ability by spermatozoa in the untreated guinea-pig coincides with rouleau formation, the significance of rouleaux in this species remains unknown. McGlinn, Shepherd \& Martan (1979) have demonstrated that rouleau formation can be blocked by treatment with cyproterone acetate without affecting the fertilizing capacity of the spermatozoa. Rouleau formation is not therefore a prerequisite for physiological maturity. However, spermatozoa in rouleau may be less vulnerable to phagocytosis by leucocytes in the female genital tract (Martan \& Shepherd, 1973). The presence of rouleaux in the epididymis could be used as a reliable indication of the physiological maturity of spermatozoa in guinea-pigs.

\section{References}

Cannon, D.C. (1974) Examination of seminal fluid. In Todd-Sanford Clinical Diagnosis by Laboratory Methods, Ch. 31, pp. 1201-1207. Eds I. Davidsohn \& J. B. Henry. W. B. Saunders Co, Philadelphia.

Fawcett, D.W. \& Hollenberg, R.D. (1963) Changes in the acrosome of guinea pig spermatozoa during passage through the epididymis. $Z$. Zellforsch. mikrosk. Anat. 60, 276-292.

Martan, J. (1966) Occurrence of the intact spermatozoa in spontaneous ejaculations of isolated male guinea pigs. Trans. Ill. St. Acad. Sci. 59, 78-80.

Martan, J. \& Shepherd, B.A. (1973) Spermatozoa in rouleaux in the female guinea pig genital tract. Anat. Rec. 175, 625-630.

Martan, J. \& Shepherd, B.A. (1976) The role of the copulatory plug in reproduction of the guinea pig. $J$. exp. Zool. 196, 79-84.

McGlinn, S.M., Shepherd, B.A. \& Martan, J. (1979) Rouleau formation and fertility of spermatozoa in guinea pigs treated with cyproterone acetate. Arch. Androl. 2, 197-202.

Shepherd, B.A. \& Martan, J. (1979) Morphology and fertility of guinea pig spermatozoa aged in vivo. Arch. Androl. 2, 53-58.

Shepherd, B.A., Martan, J. \& Murphy, R. (1974) In vitro studies of guinea pig spermatozoa in rouleaux. Biol. Reprod. 11, 470-474.

Zarrow, M.X., Yochim, J.M. \& McCarthy, J.L. (1964) Experimental Endocrinology, pp. 478. Academic Press, New York.

Received 20 December 1979 